\title{
Antimicrobial properties of nanomolecules: potential candidates as antibiotics in the era of multi-drug resistance
}

\author{
Venkataramana Kandi ${ }^{1}$, Sabitha Kandi ${ }^{2}$ \\ ${ }^{1}$ Department of Microbiology, Prathima Institute of Medical Sciences, Karimnagar; ${ }^{2}$ Department of Biochemistry, Chalmeda Anand Rao Institute \\ of Medical Sciences, Karimnagar, India
}

OBJECTIVES: The emergence of multi-drug resistance among various microbial pathogens has been a cause of serious concern to the medical world, limiting the choice of antibiotics. Considering that it may take decades to synthesize new antimicrobial drugs that combat resistant pathogens, the search for alternatives to conventional antimicrobial agents has begun.

METHODS: In his paper we attempted to review the physico-chemical properties of nanoparticles, their modes of action and potential use in medicine and research with special reference to antimicrobial properties.

RESULTS: Nanomolecules and nanoparticles have in recent years been extensively studied for their utility not only as antibiotics but also as vehicles to carry antibiotics or other agents such as cancer chemotherapeutics to target sites and limit damage to host cells.

CONCLUSION: Nanomolecules were positively evaluated for their antimicrobial activities. Anti-biofilm activities of nanoparticles, utility of nanomaterials as carrier agents of drugs signifies their importance in medicine and research.

KEY WORDS: Nanomolecules, Nanoparticles, Nanomedicine, Anti-bacterial agents

\section{INTRODUCTION}

In the current era of multi-drug resistance, in which microorganisms (i.e., viruses, bacteria, fungi, and parasites) are gaining resistance to many antimicrobial agents, it is becoming very difficult for health care workers to treat patients, leading to severe morbidity and mortality. Because the process of drug discovery and clinical trials of new antimicrobial drugs takes a long time, only a few new agents have recently been approved and are

\section{Correspondence: Venkataramana Kandi}

Department of Microbiology, Prathima Institute of Medical Sciences,

Nagunur, Karimnagar 505 417, India

Tel: +91-8728222779, Fax: +91-8728222779

E-mail: ramana_20021@rediffmail.com

Received: Feb 1, 2015, Accepted: Apr 17, 2015, Published: Apr 17, 2015

This article is available from: http://e-epih.org/

(C) 2015, Korean Society of Epidemiology

(C) This is an open-access article distributed under the terms of the Creative Commons Attribution License (http://creativecommons.org/licenses/by/3.0/), which permits unrestricted use, distribution, and reproduction in any medium, provided the original work is properly cited. available for use. The emergence and spread of microorganisms resistant to multiple antimicrobial agents (so-called 'superbugs'), due to mutations in the pathogens and overuse of antimicrobials, should be considered as a cause for serious concern. Methicillin-resistant Staphylococcus aureus, vancomycin-resistant Enterococci, Staphylococci, and Streptococci, bacteria possessing New Delhi metallobetalactamase genes coding for resistance, carbapenem resistance in many bacteria colonizing the gastrointestinal tract, and bacteria present in the environment (Pseudomonas spp. and Acinetobacter spp.) are some of the pathogens that cause infections that are difficult to treat. Mechanisms of bacterial resistance include alteration or inactivation of the antibiotic, modification of the target site of the antibiotic (e.g., penicillin-binding proteins), alteration of a metabolic pathway to avoid the disruptive effect of the antibiotic, reduced accumulation of the drug by increasing its pharmacokinetic balance towards clearance, and the secretion by bacteria of substances inhibitory to antibiotics (e.g., beta-lactamases, carbapenemases, etc.) [1-6].

Physiochemical properties of nanomolecules antimicrobial 
agents are widely used in human and veterinary medicine, as well as in water treatment and in the food (preservative) and textile industries.

Nanomolecules can be used as an alternative to conventional antimicrobial agents and can also act as carriers for antibiotics and other drugs. Nanomolecules can be synthesized from polymers, lipids, and metals [7,8]. Nanoparticles are nano-sized molecules (usually less than $100 \mathrm{~nm}$ in diameter) with a large surface area to volume ratio, which helps them to easily penetrate bacterial cells. There are numerous chemical structures of nanomolecules: they can be functionalized fullerenes (composed of carbon in the form of a hollow sphere, ellipsoid, or rod shape) or water-insoluble carbon nanotubes; liposomes (made of phospholipids or other surfactants arranged in a halo-shaped lipid bilayer); metal oxide nanoparticles; polymeric micelles (synthesized from amphiphilic polymers such as poly[ethylene glycol]$b$-poly[ع-caprolactone] polystyrene); dendrimers (highly symmetric, branched, large complex molecules); nanoshells (dielectric core surrounded by a metal coat); polymeric nanospheres (spheres of micron size); nanobins; quantum dots (semiconductors with unique optical and electrical properties); superparamagnetic iron oxide nanoparticles (SPIONs) (nanomolecules with a magnetic core coated with polysaccharides, polymers, or monomers); and polymer-coated nanocrystals (stable forms of nanomolecules). Commonly used elements in nanomolecules include gold, silver, copper, zinc, nickel, titanium, magnesium, aluminium, silicon, iron, calcium, and yttrium [9-11].

Fullerenes and functional carbon nanoparticles are used as vehicles for drug delivery and in the treatment of cancer by photothermal ablation. Liposomes are another type of nanomolecule that can carry both hydrophilic and hydrophobic molecules used in the treatment of tumours and infectious diseases. Polymeric micelles are used to deliver drugs that are water insoluble, such as amphotericin B, used for the treatment of fungal infections. Polymeric nanospheres are used to detect cancer cells. Dendrimers, quantum dots, SPIONs, and nanoshells are applied in imaging technology as well as for drug delivery in cancer treatment [10,12-14].

\section{MODE OFACTION OF NANOMOLECULES}

Nanoparticles possess unique physical, chemical, electronic, electrical, mechanical, magnetic, thermal, dielectric, optical, and biological properties. Metal oxide nanoparticles are of great interest for use as potential antimicrobial agents because of their unique optical, electronic, and magnetic properties. The electrostatic interaction of nanoparticles with negatively-charged bacterial surfaces draws the particles to the bacteria and promotes their penetration into the membrane. A strongly positive zeta potential of a nanoparticle promotes nanoparticle interactions with cell membranes leading to membrane disruption, bacterial flocculation, and a reduction in viability. The generation of reactive oxygen species is also a mechanism of nanoparticle antibacterial activity $[10,15]$.

Further mechanisms of action of nanoparticles as antimicrobial agents include disrupting deoxyribonucleic acid during the replication and cell division of microorganisms, compromising the bacterial membrane integrity via physical interactions with the microbial cell (the physical presence of a nanoparticle most likely disrupts cell membranes in a dose-dependent manner), and releasing toxic metal ions and possessing abrasive properties which bring about lysis of cells.

\section{NANOMOLECULES IN MEDICINEAND RESEARCH}

The applications of nanomolecules in medicine have recently been evaluated in reports highlighting the in vitro antimicrobial activities of nanoparticles, the use of nanomaterials in the production of implants that inhibit microbial colonization, and the possible potential adverse effects of nanomolecules on human health and the environment.

Recent studies have revealed that nanomolecules have excellent biocidal properties to eliminate Salmonella typhi and can eradicate cancer-promoting Cyanobacteria and algae (Microcystis aeruginosa) from the environment $[16,17]$. In the era of the emergence and spread of microorganisms that are multi-drug resistant, the potential antimicrobial activity of gold and silver nanomolecules should be considered as a positive indication of the utility of nanoparticles as antimicrobial agents [18].A recent report has noted the potential of silver nanomolecules against bacteria [19]. Metal oxide nanoparticles of zinc ( $\mathrm{ZnO})$, copper $(\mathrm{CuO})$ and iron $\left(\mathrm{Fe}_{2} \mathrm{O}_{3}\right)$ were studied for their antimicrobial activities against both Gram-positive bacteria (Staphylococcus aureus and Bacillus subtilis) and Gram-negative bacteria (Pseudomonas aeruginosa and Escherichia coli). This study revealed that $\mathrm{ZnO}$ nanoparticles demonstrated greatest antimicrobial activity against both Gram-positive and Gram-negative bacteria and that iron oxide nanomolecules showed the least antimicrobial potential [20]. The antibacterial and antifungal activities of $\mathrm{ZnO}$ nanoparticles were reported recently by Chitra et al. [21], who found that $\mathrm{ZnO}$ was effective against both food pathogens (E. coli and P. aeruginosa) $(100 \mu \mathrm{L})$ and Aspergillus niger (400 $\mu \mathrm{L})$ at varied concentrations. This study emphasized the utility of nanoparticles in the food packaging industry. The synthesis of nanoparticles from plant sources (green synthesis) has been an emerging field of nanoscience in the recent past. The activity of nanomolecules prepared from Allium species such as ginger and garlic, with silver as the metal $\left(\mathrm{AgNO}_{3}\right)$, showed antimicro- 
bial activity against common bacterial pathogens such as E.coli, Proteus spp., Klebsiella spp., Staphylococcus spp., Enterobacter spp., Bacillus spp., and Pseudomonas spp [22-25].

A report of the synthesis and characterization of cellulose nanocrystal nanocomposites $(\mathrm{CNC})$ applying Fourier transform infrared, ultra violet visible, X-ray diffraction, transmission electron microscopy, and thermogravimetric analyses revealed that CNC preparations of zinc oxide nanoparticles had greater antimicrobial activity against pathogenic bacteria like $S$. aureus and Salmonella choleraesuis [26]. Biogenic nanoparticles are nanomolecules naturally synthesized by the bacteria present in the environment. A very recent report demonstrated that selenium and silver nanomolecules are produced by bacteria isolated from coal mines, and that such nanoparticles have been observed to have antibacterial activity against bacteria including E. coli, Klebsiella spp., Pseudomonas spp., and S. aureus [27,28]. Antiparasitic activity of sulphur nanoparticles has also been reported in the literature, suggesting that sulphur nanomolecules were effective against nematode parasites and were not toxic to human cells [29]. Water treatment with polyacrylamide-doped magnetic iron oxide nanoparticles has shown encouraging results related to antimicrobial activity against potential bacterial pathogens, signifying the utility of nanomaterials in the purification of drinking water sources [30].

Nanoparticles have potential for external uses as antibacterial agents in surface coatings on various substrates and prosthetic devices to prevent microorganisms from attaching, colonizing, spreading, and forming bio-films on indwelling medical devices $[31,32]$. Silver-implanted titanium with a nano-structured surface was evaluated to be a good material for dental implants, due to its antimicrobial properties and osteogenic effect [33]. A recent research report on the preparation of antimicrobial denture acrylic from polymethyl methacrylate loaded with platinum nanoparticles revealed that the combination nanopreparation showed a better anti-adherent effect than bactericidal activity at a given concentration $(>50 \mathrm{mg} / \mathrm{L}$ ) [34]. A recent study evaluated the anti-tumour potential of biosynthesized gold nanoparticles on human breast cancer cell lines [35]. Finally, a very recent study has observed that stem cells treated with SPIONs can be used to treat patients suffering from cerebral ischemia or stroke [36].

Although nanomolecules have great potential in the future to become alternatives to antimicrobial agents and to provide the means for effective strategies for drug delivery in treating cancers and serious infections, the local and systemic toxic complications and the deleterious effect they have on beneficial bacteria in humans may be a cause for concern $[37,38]$. The deleterious effects of metallic nanomolecules on the environment have been studied previously, and it was found that nanoparticles released into the environment have a potentially toxic effect on microbes that are beneficial to humans [39]. Most studies have not conclusively evaluated the exact mechanism by which nanomolecules contribute to toxic complications. It has been hypothesized that the physicochemical characteristics (small size, large surface area, metal ions) that confer nanoparticles with antimicrobial properties could also lead to toxic effects in humans. Nanoparticles have the ability to spread throughout the body, cross the blood-brain barrier, and cause haemolysis, and may result in degradation products which have toxic effects and influence blood coagulation pathways. It has been observed that the larger the nanoparticle, the greater is the risk of adverse health effects [40-44]. Although nanoparticles have the potential to be used in the preparation of antimicrobial agents and carrier molecules for drug deliveries, previous reports have noted that they produce toxic hazards to the environment and human health $[45,46]$. Research is necessary to clearly understand the interaction of nanomolecules with living cells, the extent of their distribution in the human body, and their specific organ toxicity.

\section{CONCLUSION}

The available literature clearly supports the idea that nanoparticles are potential candidates to be used as antimicrobial agents. Nanomolecules can be used as anti-biofilm coats on medical devices which are used as implants in humans. Nanoparticles can be used as vehicles to enable the effective entry of antibiotics into microorganisms. Target-specific killing of tumour cells while sparing healthy human cells in the process of cancer chemotherapy is another significant application of nanomolecules. The greatest disadvantage of the usability of nanoparticles appears to be their potentially toxic side effects at higher concentrations. Further studies are warranted to improve knowledge of nanomaterials and their potential use in various fields, including and not limited to medicine, agriculture, veterinary medicine, food science and technology and environmental sciences.

\section{CONFLICT OF INTEREST}

The authors have no conflicts of interest to declare for this study.

\section{REFERENCES}

1. Kalaskar A, Venkataramana K. Determination of antimicrobial resistance pattern and production of extended-spectrum B-lactamases amongst Escherichia coli and Klebsiella pneumoniae from clinical 
isolates. J Med Bacteriol 2012;1:17-24.

2. Ramana KV, Mohanty SK, Kumar A. In-vitro activities of current antimicrobial agents against isolates of pyoderma. Indian J Dermatol Venereol Leprol 2008;74:430.

3. Ramana KV, Rao R. Significance of screening for colonization and vancomycin resistance in Staphylococcus aureus isolated from anterior nares of school going children. Online J Health Allied Sci 2009; 8:20.

4. Ramana KV, Rao R, Sharada ChV, Kareem M, Reddy LR, Ratna Mani M. Modified Hodge test: a useful and the low-cost phenotypic method for detection of carbapenemase producers in Enterobacteriaceae members. J Nat Sc Biol Med 2013;4:346-348.

5. Ramana KV, Kalaskar A, Rao M, Rao SD. Aetiology and antimicrobial susceptibility patterns of lower respiratory tract infections (LRTI's) in a rural tertiary care teaching hospital in Karimnagar, South India. Am J Infect Dis Microbiol 2013;1:101-105.

6. Sarada V, Rao R, Mani R, Ramana KV. Colistin, polymyxin B and tigecycline suspectibility to metallo betalactamase producing Acinetobacter baumannii isolated from tertiary health care hospital. Am J Microbiol Res 2014;2:60-62.

7. Chen D, Love KT, Chen Y, Eltoukhy AA, Kastrup C, Sahay G, et al. Rapid discovery of potent siRNA-containing lipid nanoparticles enabled by controlled microfluidic formulation. J Am Chem Soc 2012; 134:6948-6951.

8. Kim Y, Lee Chung B, Ma M, Mulder WJ, Fayad ZA, Farokhzad OC, et al. Mass production and size control of lipid-polymer hybrid nanoparticles through controlled microvortices. Nano Lett 2012;12:35873591.

9. Troncarelli MZ, Brandão HM, Gern JC, Guimarães AS, Langoni H. Nanotechnology and antimicrobials in veterinary medicine. Formatex 2013:543-556.

10. Thekkae Padil VV, Černík M. Green synthesis of copper oxide nanoparticles using gum karaya as a biotemplate and their antibacterial application. Int J Nanomedicine 2013;8:889-898.

11. Kon K, Rai M. Metallic nanoparticles: mechanism of antibacterial action and influencing factors. J Comp Clin Path Res 2013;2:160174.

12. Dian L, Yang Z, Li F, Wang Z, Pan X, Peng X, et al. Cubic phase nanoparticles for sustained release of ibuprofen: formulation, characterization, and enhanced bioavailability study. Int J Nanomedicine 2013;8:845-854.

13. Abboud Y, Saffaj T, Chagraoui A, El Bouari A, Brouzi K, Tanane B, et al. Biosynthesis, characterization and antimicrobial activity of copper oxide nanoparticles (CONPs) produced using brown alga extract (Bifurcaria bifurcata). Appl Nanosci 2014;4:571-576.

14. Leuba KD, Durmus NG, Taylor EN, Webster TJ. Short communication: carboxylate functionalized superparamagnetic iron oxide nanoparticles (SPION) for the reduction of S. aureus growth post biofilm formation. Int J Nanomedicine 2013:8:731-736.

15. Hajipour MJ, Fromm KM, Ashkarran AA, Jimenez de Aberasturi D, de Larramendi IR, Rojo T, et al. Antibacterial properties of nanoparticles. Trends Biotechnol 2012;31:61-62.

16. Lima E, Guerra R, Lara V, Guzmán A. Gold nanoparticles as efficient antimicrobial agents for Escherichia coli and Salmonella typhi. Chem Cent J 2013;7:11.

17. El-Sheekh MM, El-Kassas HY. Application of biosynthesized silver nanoparticles against a cancer promoter cyanobacterium, Microcystis aeruginosa. Asian Pac J Cancer Prev 2014;15:6773-6779.

18. Zhou Y, Kong Y, Kundu S, Cirillo JD, Liang H. Antibacterial activities of gold and silver nanoparticles against Escherichia coli and bacillus Calmette-Guérin. J Nanobiotechnology 2012;10:19.
19. Yu L, Zhang Y, Zhang B, Liu J. Enhanced antibacterial activity of silver nanoparticles/halloysite nanotubes/graphene nanocomposites with sandwich-like structure. Sci Rep 2014;4:4551.

20. Azam A, Ahmed AS, Oves M, Khan MS, Habib SS, Memic A. Antimicrobial activity of metal oxide nanoparticles against Gram-positive and Gram-negative bacteria: a comparative study. Int J Nanomedicine 2012;7:6003-6009.

21. Chitra K, Annadurai G. Antimicrobial activity of wet chemically engineered spherical shaped $\mathrm{ZnO}$ nanoparticles on food borne pathogen. Int Food Res J 2013;20:59-64.

22. Lekshmi NC, Sumi SB, Viveka S, Jeeva S, Brindha JR. Antibacterial activity of nanoparticles from Allium sp. J Microbiol Biotechnol Res 2012;2:115-119.

23. El Kassas HY, Attia AA. Bactericidal application and cytotoxic activity of biosynthesized silver nanoparticles with an extract of the red seaweed Pterocladiella capillacea on the HepG2 cell line. Asian Pac J Cancer Prev 2014;15:1299-1306.

24. Aramwit P, Bang N, Ratanavaraporn J, Ekgasit S. Green synthesis of silk sericin-capped silver nanoparticles and their potent anti-bacterial activity. Nanoscale Res Lett 2014;9:79.

25. Yasin S, Liu L, Yao J. Biosynthesis of silver nanoparticles by bamboo leaves extract and their antimicrobial activity. J Fiber Bioeng Inform 2013;6:77-84.

26. Azizi S, Ahmad M, Mahdavi M, Abdolmohammadi S. Preparation, characterization, and antimicrobial activities of $\mathrm{ZnO}$ nanoparticles/ cellulose nanocrystal nanocomposites. BioResources 2013;8:18411851.

27. Singh N, Saha P, Rajkumar K, Abraham J. Biosynthesis of silver and selenium nanoparticles by Bacillus sp. JAPSK2 and evaluation of antimicrobial activity. Der Pharm Lett 2014;6:175-181.

28. Deepa S, Kanimozhi K, Panneerselvam A. Antimicrobial activity of extracellularly synthesized silver nanoparticles from marine derived actinomycetes. Int J Curr Microbiol App Sci 2013;2:223-230.

29. Schneider T, Baldauf A, Ba LA, Jamier V, Khairan K, Sarakbi MB, et al. Selective antimicrobial activity associated with sulfur nanoparticles. J Biomed Nanotechnol 2011;7:395-405.

30. Mukherje M. In vitro antimicrobial activity of polyacrylamide doped magnetic iron oxide nanoparticles. Int J Mater Mech Manuf 2014;2: 64-66.

31. Soto SM. Importance of biofilms in urinary tract infections: new therapeutic approaches. Adv Biol 2014;2014:543974.

32. Ahamed M, Alhadlaq HA, Majeed Khan MA, Karuppiah P, Al-Dhabi NA. Synthesis, characterization, and antimicrobial activity of copper oxide nanoparticles. J Nanomater 2014;2014:637858.

33. Zheng Y, Li J, Liu X, Sun J. Antimicrobial and osteogenic effect of Ag-implanted titanium with a nanostructured surface. Int J Nanomedicine 2012;7:875-884.

34. Nam KY. Characterization and bacterial anti-adherent effect on modified PMMA denture acrylic resin containing platinum nanoparticles. J Adv Prosthodont 2014;6:207-214.

35. El-Kassas HY, El-Sheekh MM. Cytotoxic activity of biosynthesized gold nanoparticles with an extract of the red seaweed Corallina officinalis on the MCF-7 human breast cancer cell line. Asian Pac J Cancer Prev 2014; 15:4311-4317.

36. Nucci LP, Silva HR, Giampaoli V, Mamani JB, Nucci MP, Gamarra LF. Stem cells labeled with superparamagnetic iron oxide nanoparticles in a preclinical model of cerebral ischemia: a systematic review with meta-analysis. Stem Cell Res Ther 2015;6:27.

37. Zhang L, Pornpattananangku D, Hu CM, Huang CM. Development of nanoparticles for antimicrobial drug delivery. Curr Med Chem 2010;17:585-594. 
38. Prabhu S, Poulose EK. Silver nanoparticles: mechanism of antimicrobial action, synthesis, medical applications, and toxicity effects. Int Nano Lett 2012;2:32.

39. Gajjar P, Pettee B, Britt DW, Huang W, Johnson WP, Anderson AJ. Antimicrobial activities of commercial nanoparticles against an environmental soil microbe, Pseudomonas putida KT2440. J Biol Eng 2009;3:9.

40. De Jong WH, Borm PJ. Drug delivery and nanoparticles:applications and hazards. Int J Nanomedicine 2008;3:133-149.

41. Buzea C, Pacheco Blandino II, Robbie K. Nanomaterials and nanoparticles: sources and toxicity. Biointerphases 2007;2:MR17-MR71.

42. European Commission. Scientific committee on emerging and newly identified health risks (SCENIHR) modified opinion (after public consultation) on the appropriateness of existing methodologies to assess the potential risks associated with engineered and adventitious products of nanotechnologies; 2006 [cited 2015 Mar 18]. Available from: http://ec.europa.eu/health/ph_risk/committees/04_scenihr/docs/ scenihr_o_003b.pdf.

43. Sayes $\bar{C}$, Liang F, Hudson JL, Mendez J, Guo W, Beach JM, et al. Functionalization density dependence of single-walled carbon nanotubes cytotoxicity in vitro. Toxicol Lett 2006;161:135-142.

44. Schins RP, Lightbody JH, Borm PJ, Shi T, Donaldson K, Stone V. Inflammatory effects of coarse and fine particulate matter in relation to chemical and biological constituents. Toxicol Appl Pharmacol 2004; 195:1-11.

45. Donaldson K, Aitken R, Tran L, Stone V, Duffin R, Forrest G, et al. Carbon nanotubes: a review of their properties in relation to pulmonary toxicology and workplace safety. Toxicol Sci 2006;92:5-22.

46. Dreher KL. Health and environmental impact of nanotechnology: toxicological assessment of manufactured nanoparticles. Toxicol Sci 2004;77:3-5. 